\title{
Periodic boundary value problems for second-order functional differential equations with impulse
}

\section{Yulin Zhao ${ }^{1 *}$, Haibo Chen ${ }^{2}$ and Bin Qin ${ }^{3}$}

\section{${ }^{*}$ Correspondence:}

zhaoylch@sina.com

'School of Science, Hunan

University of Technology, Zhuzhou,

Hunan 412007, P.R. China

Full list of author information is

available at the end of the article

\begin{abstract}
In this paper, we study the existence of multiple positive solutions of the second-order periodic boundary value problems for functional differential equations with impulse. The proof of our main results is based upon the fixed point index theorem in cones.

Keywords: boundary value problem; impulsive functional differential equations; multiple solutions; cones
\end{abstract}

\section{Introduction}

In this paper, we will consider the existence of positive solutions for boundary value problems of second order impulsive functional differential equations of the form

$$
\left\{\begin{array}{l}
\left(\rho(t) u^{\prime}(t)\right)^{\prime}+f\left(t, u_{t}\right)=0, \quad t \in J, t \neq t_{k}, k=1, \ldots, m \\
-\Delta u^{\prime}\left(t_{k}\right)=I_{k}\left(u_{t_{k}}\right), \quad k=1,2, \ldots, m, \\
u_{0}=\varphi, \quad u(T)=A
\end{array}\right.
$$

where $J=[0, T], f: J \times C_{\tau} \rightarrow R$ is a continuous function, $\varphi \in C_{\tau}\left(C_{\tau}\right.$ be given in Section 2), $\tau \geq 0, \rho(t) \in C(J,(0, \infty)), u_{t} \in C_{\tau}, u_{t}(\theta)=u(t+\theta), \theta \in[-\tau, 0] . I_{k} \in C\left(C_{\tau}, R\right), 0=t_{0}<t_{1}<$ $t_{2}<\cdots<t_{m}<t_{m+1}=T, J^{\prime}=(0, T) \backslash\left\{t_{1}, \ldots, t_{m}\right\} . \Delta u^{\prime}\left(t_{k}\right)=u^{\prime}\left(t_{k}^{+}\right)-u^{\prime}\left(t_{k}^{-}\right), u^{\prime}\left(t_{k}^{+}\right)\left(u^{\prime}\left(t_{k}^{-}\right)\right)$denote the right limit (left limit) of $u^{\prime}(t)$ at $t=t_{k}$, and $A \in R=(-\infty,+\infty)$.

Impulsive differential equations describe processes which experience a sudden change of their state at certain moments. The theory of impulse differential equations has been a significant development in recent years and played a very important role in modern applied mathematical models of real processes arising in phenomena studied in physics, population dynamics, chemical technology and biotechnology; see [1-3].

Many papers have been published about the existence analysis of periodic boundary value problems of first and second order for ordinary or functional or integro-differential equations with impulsive. We refer the readers to the papers [4-23]. For instance, in [6], $\mathrm{He}$ and $\mathrm{Yu}$ investigated the following problem:

$$
\left\{\begin{array}{l}
u^{\prime}(t)=f\left(t, u(t), u_{t}\right), \quad t \neq t_{k}, 0<t<T, \\
\Delta u\left(t_{k}\right)=I_{k}\left(u\left(t_{k}\right)\right), \quad k=1,2, \ldots, m, \\
u(t)=u(0), \quad t \in[-\tau, 0), \\
u(0)=u(T) .
\end{array}\right.
$$

@2014 Zhao et al.; licensee Springer. This is an Open Access article distributed under the terms of the Creative Commons Attribution License (http://creativecommons.org/licenses/by/2.0), which permits unrestricted use, distribution, and reproduction in any medium, provided the original work is properly cited. 
By using the coincidence degree, Dong [4] studied the following periodic boundary value problems (PBVP) for first-order functional differential equations with impulse:

$$
\left\{\begin{array}{l}
u^{\prime}(t)=f\left(t, u_{t}\right), \quad t \neq t_{k}, 0<t<T, \\
\Delta u\left(t_{k}\right)=I_{k}\left(u\left(t_{k}\right)\right), \quad k=1,2, \ldots, m, \\
u(0)=u(T) .
\end{array}\right.
$$

It is remarkable that the author required $u(t)=u(t+1)$ for $t \in[-\tau, 0]$. The author also obtained the existence of one solution of PBVP (1.2).

To study periodic boundary value problems for first and second order functional differential equations with impulse, the approaches used in $[4,6-8,13-16,20-23]$ are the monotone iterative technique and the method of upper and lower solutions. What they obtained is the existence of at least one solution if there is a pair of upper and lower solutions. However, in some cases it is difficult to find upper and lower solutions for general differential equations.

As we know, the fixed point theorem of cone expression and compression is extensively used to study the existence of multiple solutions of boundary value problems for secondorder differential equations. In paper [5], Ma considers the following periodic boundary value problem:

$$
\left\{\begin{array}{l}
u^{\prime \prime}(t)+f\left(t, u_{t}\right)=0, \quad 0<t<T, \\
u_{0}=\varphi, \quad u(T)=A,
\end{array}\right.
$$

and he obtained some sufficient conditions for the existence of at least one positive solution of the PBVP (1.3).

In [19], by applying the fixed point theorem of cone expression and compression, Liu investigates the existence of multiple positive solutions of the following problem:

$$
\left\{\begin{array}{l}
u^{\prime}(t)=f\left(t, u_{t}\right), \quad t \neq t_{k}, t \in(0, T), \\
\Delta u\left(t_{k}\right)=I_{k}\left(u\left(t_{k}\right)\right), \quad k=1,2, \ldots, m, \\
u(t)=\varphi(t), \quad t \in[-\tau, 0], \\
u(0)=u(T) .
\end{array}\right.
$$

Motivated by the results in $[5,19,24]$, the aim of this paper is to consider the existence of multiple positive solutions for the PBVP (1.1) by using some properties of the Green function and the fixed point index theorem in cones.

This paper will be divided into three sections. In Section 2, we provide some preliminaries and establish several lemmas which will be used throughout Section 3. In Section 3, we shall give the existence theorems of multiplicity positive solutions of PBVP (1.1).

\section{Preliminary and lemmas}

Let $C_{\tau}:=\{\varphi:[-\tau, 0] \rightarrow R ; \varphi(t)$ is continuous everywhere except for a finite number of points $\bar{t}$ at which $\varphi\left(\bar{t}^{+}\right)$and $\varphi\left(\bar{t}^{-}\right)$exist and $\left.\varphi\left(\bar{t}^{-}\right)=\varphi(\bar{t})\right\}$, then $C_{\tau}$ is a normed space with the norm

$$
\|\varphi\|_{[-\tau, 0]}=\sup _{\theta \in[-\tau, 0]}|\varphi(\theta)|, \quad \forall \varphi \in C_{\tau} .
$$


Let $J^{*}=[-\tau, T], C\left(J^{*}\right)$ and $C^{1}\left(J^{*}\right)$ represent the set of a continuous and continuously differentiable on $J^{*}$, respectively. Moreover, for $u \in C\left(J^{*}\right)$ we define $\|u\|_{J^{*}}=\sup _{t \in J^{*}}|u(t)|$. Furthermore, we denote:

$P C\left(J^{*}\right)=\left\{u: u(t)\right.$ is a map from $J^{*}$ into $R$ such that $u(t)$ is continuous at $t \neq t_{k}$, and $u\left(t_{k}^{+}\right), u\left(t_{k}^{-}\right)$exist and $u\left(t_{k}^{-}\right)=u\left(t_{k}\right)$ for $k=1,2, \ldots, m ; u(t)=\varphi(t)$ for $\left.t \in[-\tau, 0]\right\}$.

$P C^{1}\left(J^{*}\right)=\left\{u \in P C\left(J^{*}\right):\left.u\right|_{\left(t_{k}, t_{k+1}\right)} \in C^{1}\left(t_{k}, t_{k+1}\right), u^{\prime}\left(t_{k}^{-}\right)\right.$and $u^{\prime}\left(t_{k}^{+}\right)$exist; and $u^{\prime}\left(t_{k}^{-}\right)=u^{\prime}\left(t_{k}\right)$ for $k=1,2, \ldots, m\} . P C^{+}\left(J^{*}\right)=\left\{u \in P C\left(J^{*}\right): u(t) \geq 0, t \in[-\tau, T]\right\}$.

Clearly, $P C\left(J^{*}\right)$ is a Banach space with the norm $\|u\|_{J^{*}}=\sup _{t \in J^{*}}|u(t)|$ for $u(t) \in P C\left(J^{*}\right)$. $P C^{1}\left(J^{*}\right)$ is also a Banach space with the norm $\|u\|_{1}=\max \left\{\|u\|_{J^{*}},\left\|u^{\prime}\right\|_{J^{*}}\right\}$.

We need to assume the following conditions:

(A1) $1-\int_{0}^{T} G(s, s) d s>0 ; \varphi(\theta) \geq 0$ for $\theta \in[-\tau, 0]$, and $A \geq \phi(0)$;

(A2) $f(t, u) \geq 0$ for $t \in[0, T]$ and $u \in P C^{+}\left(J^{*}\right)$;

(A3) $I_{k}(k=1,2, \ldots, m)$ are continuous and $I_{k}(u) \geq 0$ for $u \in P C^{+}\left(J^{*}\right)$.

Lemma 2.1 (see [25]) Let E be a Banach spaces and $K \subset E$ be a cone in E. Let $r>0$ and $\Omega_{r}=\{x \in K:\|x\|<r\}$. Assume that $S: \bar{\Omega}_{r} \rightarrow K$ is a completely continuous operator such that $S x \neq x$ for $x \in \partial \Omega_{r}$.

(i) If $\|S x\| \leq\|x\|$ for $x \in \partial \Omega_{r}$, then $i\left(S, \Omega_{r}, K\right)=1$.

(ii) If $\|S x\| \geq\|x\|$ for $x \in \partial \Omega_{r}$, then $i\left(S, \Omega_{r}, K\right)=0$.

Lemma 2.2 For any $y, a_{k} \in P C(J, R)$, and $\eta, A \in R$. Then the problem

$$
\left\{\begin{array}{l}
\left(\rho(t) u^{\prime}(t)\right)^{\prime}+y(t)=0, \quad t \in J, t \neq t_{k}, k=1,2, \ldots, m, \\
-\Delta u^{\prime}\left(t_{k}\right)=a_{k}, \quad k=1,2, \ldots, m, \\
u(0)=\eta, \quad u(T)=A
\end{array}\right.
$$

has a unique solution

$$
u(t)=\eta+\frac{(A-\eta)}{\phi(T)} \phi(t)+\int_{0}^{T} G(t, s) y(s) d s+\sum_{0<t_{k}<T} G\left(t, t_{k}\right) \rho\left(t_{k}\right) a_{k},
$$

where

$$
G(t, s)=\frac{1}{\phi(T)}\left\{\begin{array}{ll}
(\phi(T)-\phi(t)) \phi(s), & 0 \leq s \leq t \leq T, \\
\phi(t)(\phi(T)-\phi(s)), & 0 \leq t \leq s \leq T,
\end{array} \quad \phi(t)=\int_{0}^{t} \frac{d s}{\rho(s)}<+\infty .\right.
$$

Proof Integrating the first equation of (2.1) over the interval $[0, t]$ for $t \in[0, T)$, we get

$$
u(t)=u(0)+\rho(0) u^{\prime}(0) \phi(t)-\int_{0}^{t}[\phi(t)-\phi(s)] y(s) d s-\sum_{0<t_{k}<t}\left[\phi(t)-\phi\left(t_{k}\right)\right] \rho\left(t_{k}\right) a_{k} .
$$

It follows from the boundary conditions $u(0)=\eta, u(T)=A$ and (2.4) that

$$
u^{\prime}(0)=\frac{1}{\rho(0) \phi(T)}\left[(A-\eta)+\int_{0}^{T}[\phi(T)-\phi(s)] y(s) d s+\sum_{0<t_{k}<T}\left[\phi(T)-\phi\left(t_{k}\right)\right] \rho\left(t_{k}\right) a_{k}\right] .
$$

Together with (2.4), we obtain (2.2).

By the standard discussion, we have the following lemma which will be used later. 
Lemma 2.3 The Green function $G(t, s)$ defined in (2.3) has the following properties:

(i) $G(t, s) \geq 0, \forall t, s \in[0, T]$;

(ii) $G(t, s) \leq G(s, s)<+\infty, \forall t, s \in[0, T]$;

(iii) $0<\sigma G(s, s) \leq G(t, s), \forall t \in[\alpha, \beta], s \in[0, T]$, where $\alpha \in\left(0, t_{1}\right], \beta \in\left[t_{m}, T\right)$, and

$$
0<\sigma:=\min \left\{\frac{\phi(T)-\phi(\beta)}{\phi(T)-\phi(\alpha)}, \frac{\phi(\alpha)}{\phi(\beta)}\right\}<1
$$

Form Lemma 2.2, the problem (1.1) is equivalent to the integral equation:

$$
(S u)(t):=u(t)=\left\{\begin{array}{cc}
\varphi(0)+\frac{(A-\varphi(0))}{\phi(T)} \phi(t)+\int_{0}^{T} G(t, s) f\left(s, u_{s}\right) d s & \\
\quad+\sum_{0<t_{k}<T} G\left(t, t_{k}\right) \rho\left(t_{k}\right) I_{k}\left(u_{t_{k}}\right), & t \in[0, T], \\
\varphi(t), & t \in[-\tau, 0] .
\end{array}\right.
$$

Definition 2.4 A function $u \in P C^{1}\left(J^{*}\right) \cap C^{2}(J)$ is called a positive solution of PBVP (1.1), if it satisfies the PBVP (1.1) and $u(t) \geq 0$ on $J^{*}$, and $u(t) \not \equiv 0$ on $J$.

Define a cone $K$ in $P C\left(J^{*}\right)$ as follows:

$$
K=\left\{x \in P C\left(J^{*}\right): x \geq 0 \text { on } J^{*} \text { and } x(t) \geq \sigma\|x\|_{[0, T]}, \forall t \in[\alpha, \beta]\right\} .
$$

Lemma 2.5 The operator $S: K \rightarrow K$ is completely continuous.

Proof It is easy to show that $S(K) \subseteq K$ holds. Let $B$ be a bounded subset in $P C\left(J^{*}\right)$. By virtue of the Ascoli-Arzela theorem, we only show that $S(B)$ is bounded in $P C\left(J^{*}\right)$ and $S(B)$ is equicontinuous. For any $u \in C_{\tau}$ and $\theta \in[-\tau, 0], t \in[0, T]$, we have $u_{t}(\theta)=u(t+\theta)$. Therefore, the set $\left\{u_{t}: u \in B, t \in[0, T]\right\}$ is uniformly bounded with respect to $t \in[0, T]$ on $C_{\tau}$. Then there exist two constants $L_{1}>0, L_{2}>0$ such that

$$
\max _{u \in B, s \in[0, T]}\left\{\left|f\left(s, u_{s}\right)\right|\right\}<L_{1}, \quad \max _{u \in B, 0<t_{k}<T}\left\{\left|I_{k}\left(u_{t_{k}}\right)\right|\right\}<L_{2}, \quad k=1,2, \ldots, m .
$$

Taking

$$
L=\max _{t, s \in[0, T]}\{|G(t, s)|\}, \quad L_{0}=\max _{t, t_{k} \in[0, T]}\left\{\left|G\left(t, t_{k}\right)\right|\right\}, \quad k=1,2, \ldots, m .
$$

It follows from (2.5), (2.7), and (2.8) that $S(B)$ is bounded in $P C\left(J^{*}\right)$.

Let $u \in B$ and $t, t^{\prime} \in[-\tau, T]$ with $t<t^{\prime}$. There are three possibilities:

Case I. If $0 \leq t<t^{\prime} \leq T$, then

$$
\begin{aligned}
\left|(S u)(t)-(S u)\left(t^{\prime}\right)\right| \leq & \int_{0}^{T}\left|G(t, s)-G\left(t^{\prime}, s\right)\right| f\left(s, u_{s}\right) d s \\
& +\frac{A-\phi(0)}{\phi(T)}\left|\phi(t)-\phi\left(t^{\prime}\right)\right| \\
& +\sum_{0<t_{k}<T}\left|G\left(t, t_{k}\right)-G\left(t^{\prime}, t_{k}\right)\right| \rho\left(t_{k}\right) I_{k}\left(u_{t_{k}}\right) .
\end{aligned}
$$

Case II. If $-\tau \leq t<t^{\prime} \leq 0$, then we have $\left|(S u)(t)-(S u)\left(t^{\prime}\right)\right|=\left|\varphi(t)-\varphi\left(t^{\prime}\right)\right|$. 
Case III. If $-\tau \leq t<0<t^{\prime} \leq T$, then

$$
\begin{aligned}
\left|(S u)(t)-(S u)\left(t^{\prime}\right)\right| \leq & \left|(S u)\left(t^{\prime}\right)-(S u)(0)\right|+|(S u)(0)-(S u)(t)| \\
\leq & \int_{0}^{T}\left|G\left(t^{\prime}, s\right)-G(0, s)\right| f\left(s, u_{s}\right) d s \\
& +\frac{A-\varphi(0)}{\phi(T)}|\phi(t)-0|+|\varphi(0)-\varphi(t)| \\
& +\sum_{0<t_{k}<T}\left|G\left(t^{\prime}, t_{k}\right)-G\left(0, t_{k}\right)\right| \rho\left(t_{k}\right) I_{k}\left(u_{t_{k}}\right) .
\end{aligned}
$$

Clearly, in either case, it follows from the continuity of $G(t, s)$ and the uniform continuity of $\varphi$ in $[-\tau, 0]$ that for any $\varepsilon>0$, there exists a positive constant $\delta$, independent of $t$, $t^{\prime}$ and $u$, whenever $\left|t-t^{\prime}\right|<\delta$, such that $\left|(S u)(t)-S(u)\left(t^{\prime}\right)\right| \leq \varepsilon$ holds. Therefore, $S(B)$ is equicontinuous.

\section{The main results}

In this section, we shall consider the existence of multiple positive solutions for the periodic boundary value problems (1.1).

For convenience sake, we set

$$
f_{\infty}:=\lim _{v \in P C^{+},\|v\|_{[-\tau, 0]} \rightarrow \infty} \frac{f(t, v)}{\|v\|_{[-\tau, 0]}}, \quad I_{k}^{\infty}:=\lim _{v \in P C^{+},\|v\|_{[-\tau, 0]} \rightarrow \infty} \frac{I_{k}(v)}{\|v\|_{[-\tau, 0]}}, \quad k=1,2, \ldots, m .
$$

For the first theorem we need the following hypotheses:

(C1) There exists a constant $a_{1}>0$ such that for $v \in P C^{+}\left(J^{*}\right):\|v\|_{[-\tau, 0]} \leq a_{1}$,

$$
\begin{aligned}
& f(t, v) \geq M_{0} \max \left\{\|v\|_{[-\tau, 0]},\|\varphi\|_{[-\tau, 0]}\right\}, \quad \forall t \in[0, T], \\
& I_{k}(v) \geq M_{k} \max \left\{\|v\|_{[-\tau, 0]},\|\varphi\|_{[-\tau, 0]}\right\}, \quad k=1,2, \ldots, m,
\end{aligned}
$$

where $M_{0}$ and $M_{k}$ are two positive constants satisfying:

$$
\sigma\left\{M_{0} \int_{\alpha}^{\beta} G\left(\frac{1}{2}, s\right) d s+\sum_{\alpha<t_{k}<\beta} G\left(\frac{1}{2}, t_{k}\right) \rho\left(t_{k}\right) M_{k}\right\} \geq 1
$$

(C2) There exists a constant $b_{1}>0$ satisfying:

$$
b_{1}>\max \left\{\|\varphi\|_{[-\tau, 0]}, a_{1},(1-D)^{-1} A\right\} \quad(D \text { be given in }(3.2))
$$

such that

$$
f(t, v) \leq M_{0}^{*}\|v\|_{[-\tau, 0]}, \quad \forall t \in[0, T] \quad \text { and } \quad I_{k}(v) \leq M_{k}^{*}\|v\|_{[-\tau, 0]}, \quad k=1,2, \ldots, m
$$

for $v \in P C^{+}\left(J^{*}\right):\|v\|_{[-\tau, 0]} \leq b_{1}$, where $M_{0}^{*}>0, M_{k}^{*}>0$ are constants satisfying:

$$
D:=\max _{t \in[0, T]}\left\{M_{0}^{*} \int_{0}^{T} G(t, s) d s+\sum_{k=1}^{m} G\left(t, t_{k}\right) \rho\left(t_{k}\right) M_{k}^{*}\right\}<1 .
$$

Theorem 3.1 Assume that (C1), (C2), $f_{\infty}=\infty$, and $I_{k}^{\infty}=\infty$ hold. Then PBVP (1.1) has at least two positive solutions $u_{*}$, $u_{* *}$ with $0<\left\|u_{*}\right\|_{[-\tau, T]}<b_{1}<\left\|u_{* *}\right\|_{[-\tau, T]}$. 
Proof For any $u \in K$, we have $u(t) \geq \sigma\|u\|_{[0, T]}, t \in[\alpha, \beta]$. It follows from the definitions of $P C\left(J^{*}\right)$ and $u_{t}$ that

$$
\left\|u_{s}\right\|_{[-\tau, 0]}=\sup _{\theta \in[-\tau, 0]}|u(s+\theta)| \geq u(s) \geq \sigma\|u\|_{[0, T]} .
$$

Then for $u \in K$ with $\|u\|_{[-\tau, T]}=a_{1}$, it follows from (2.5) and assumption (C1) that

$$
\begin{aligned}
(S u)\left(\frac{1}{2}\right)= & \varphi(0)+\frac{(A-\varphi(0))}{\phi(T)} \phi\left(\frac{1}{2}\right)+\int_{0}^{T} G\left(\frac{1}{2}, s\right) f\left(s, u_{s}\right) d s \\
& +\sum_{0<t_{k}<T} G\left(\frac{1}{2}, t_{k}\right) \rho\left(t_{k}\right) I_{k}\left(u_{t_{k}}\right) \\
\geq & \int_{0}^{T} G\left(\frac{1}{2}, s\right) f\left(s, u_{s}\right) d s+\sum_{0<t_{k}<T} G\left(\frac{1}{2}, t_{k}\right) \rho\left(t_{k}\right) I_{k}\left(u_{t_{k}}\right) \\
\geq & \int_{0}^{T} G\left(\frac{1}{2}, s\right) M_{0} \max \left\{\left\|u_{s}\right\|_{[-\tau, 0]},\|\varphi\|_{[-\tau, 0]}\right\} d s \\
& +\sum_{0<t_{k}<T} G\left(\frac{1}{2}, t_{k}\right) \rho\left(t_{k}\right) M_{k} \max \left\{\left\|u_{t_{k}}\right\|_{[-\tau, 0]},\|\varphi\|_{[-\tau, 0]}\right\} \\
\geq & \int_{\alpha}^{\beta} G\left(\frac{1}{2}, s\right) M_{0} \max \left\{\left\|u_{s}\right\|_{[-\tau, 0]},\|\varphi\|_{[-\tau, 0]}\right\} d s \\
& +\sum_{\alpha<t_{k}<\beta} G\left(\frac{1}{2}, t_{k}\right) \rho\left(t_{k}\right) M_{k} \max \left\{\left\|u_{t_{k}}\right\|_{[-\tau, 0]},\|\varphi\|_{[-\tau, 0]}\right\} \\
\geq & \int_{\alpha}^{\beta} G\left(\frac{1}{2}, s\right) M_{0} \max \left\{\sigma\|u\|_{[0, T]},\|\varphi\|_{[-\tau, 0]}\right\} d s \\
& +\sum_{\alpha<t_{k}<\beta} G\left(\frac{1}{2}, t_{k}\right) \rho\left(t_{k}\right) M_{k} \max \left\{\sigma\|u\|_{[0, T]},\|\varphi\|_{[-\tau, 0]}\right\} \\
\geq & \sigma\left\{M_{0} \int_{\alpha}^{\beta} G\left(\frac{1}{2}, s\right) d s+\sum_{\alpha<t_{k}<\beta} G\left(\frac{1}{2}, t_{k}\right) \rho\left(t_{k}\right) M_{k}\right\}\|u\|_{[-\tau, T]} \\
\geq & \|u\|_{[-\tau, T]}=a_{1} . \\
&
\end{aligned}
$$

Now if we set $\Omega_{a_{1}}=\left\{u \in K:\|u\|_{[-\tau, T]}<a_{1}\right\}$, then (3.4) shows that $\|S u\|_{[-\tau, T]} \geq\|u\|_{[-\tau, T]}$ for $u \in \partial \Omega_{a_{1}}$. Thus, Lemma 2.1 yields

$$
i\left(S, \Omega_{a_{1}}, K\right)=0 .
$$

For $u \in K$ with $\|u\|_{[-\tau, T]}=b_{1}$, from (2.5) and assumption (C2), we have

$$
\begin{aligned}
|S u(t)| & = \begin{cases}\mid \varphi(0)+\frac{(A-\varphi(0))}{\phi(T)} \phi(t)+\int_{0}^{T} G(t, s) f\left(s, u_{s}\right) d s \\
+\sum_{0<t_{k}<T} G\left(t, t_{k}\right) \rho\left(t_{k}\right) I_{k}\left(u_{t_{k}}\right) \mid, & t \in[0, T], \\
|\varphi(t)|, & t \in[-\tau, 0]\end{cases} \\
& \leq\left\{\begin{array}{l}
\int_{0}^{T} G(t, s) M_{0}^{*}\left\|u_{s}\right\|_{[-\tau, 0]} d s+\sum_{0<t_{k}<T} G\left(t, t_{k}\right) \rho\left(t_{k}\right) M_{k}^{*}\left\|u_{t_{k}}\right\|_{[-\tau, 0]}+A, \\
\|\varphi\|_{[-\tau, 0]}
\end{array}\right.
\end{aligned}
$$




$$
\begin{aligned}
& \leq\left\{\begin{array}{l}
\max _{t \in[0, T]}\left\{M_{0}^{*} \int_{0}^{T} G(t, s)\left\|u_{s}\right\|_{[-\tau, 0]} d s\right. \\
\left.\quad+\sum_{0<t_{k}<T} G\left(t, t_{k}\right) \rho\left(t_{k}\right) M_{k}^{*}\left\|u_{t_{k}}\right\|_{[-\tau, 0]}\right\}+A, \\
\|\varphi\|_{[-\tau, 0]}
\end{array}\right. \\
& \leq\left\{\begin{array}{l}
D b_{1}+A \\
\|\varphi\|_{[-\tau, 0]}
\end{array}\right. \\
& <b_{1} .
\end{aligned}
$$

Set $\Omega_{b_{1}}=\left\{u \in K:\|u\|_{[-\tau, T]}<b_{1}\right\}$. Then (3.6) shows that $\|S u\|_{[-\tau, T]}<\|u\|_{[-\tau, T]}$ for $u \in \partial \Omega_{b_{1}}$.

Hence, Lemma 2.1 implies that

$$
i\left(S, \Omega_{b_{1}}, K\right)=1
$$

According to $f_{\infty}=\infty$ and $I_{k}^{\infty}=\infty$, choose a constant $b^{*}$ such that

$$
b^{*}>\max \left\{\|\varphi\|_{[-\tau, 0]}, b_{1}\right\}
$$

and

$$
\begin{aligned}
& f(t, v) \geq \bar{M}_{0}\|v\|_{[-\tau, 0]}, \quad \forall t \in[0, T], \forall v \in P C^{+}\left(J^{*}\right), \sigma b^{*} \leq\|v\|_{[-\tau, 0]}, \\
& I_{k}(v) \geq \bar{M}_{k}\|v\|_{[-\tau, 0]}, \quad \forall v \in P C^{+}\left(J^{*}\right), \sigma b^{*} \leq\|v\|_{[-\tau, 0]}, k=1,2, \ldots, m,
\end{aligned}
$$

where $\bar{M}_{0}>0, \bar{M}_{k}>0$ are constants satisfying:

$$
\sigma\left\{\bar{M}_{0} \int_{\alpha}^{\beta} G\left(\frac{1}{2}, s\right) d s+\sum_{\alpha<t_{k}<\beta} G\left(\frac{1}{2}, t_{k}\right) \rho\left(t_{k}\right) \bar{M}_{k}\right\}>1 .
$$

For $u \in K$ with $\|u\|_{[-\tau, T]}=b^{*}$, from (2.5), Lemma 2.5 and (3.9), by using the same method to get (3.3), we can get

$$
\begin{aligned}
(\text { Su })\left(\frac{1}{2}\right)= & \varphi(0)+\frac{(A-\varphi(0))}{\phi(T)} \phi\left(\frac{1}{2}\right)+\int_{0}^{T} G\left(\frac{1}{2}, s\right) f\left(s, u_{s}\right) d s \\
& +\sum_{0<t_{k}<T} G\left(\frac{1}{2}, t_{k}\right) \rho\left(t_{k}\right) I_{k}\left(u_{t_{k}}\right) \\
\geq & \int_{\alpha}^{\beta} G\left(\frac{1}{2}, s\right) \bar{M}_{0}\left\|u_{s}\right\|_{[-\tau, 0]} d s+\sum_{\alpha<t_{k}<\beta} G\left(\frac{1}{2}, t_{k}\right) \rho\left(t_{k}\right) \bar{M}_{k}\left\|u_{t_{k}}\right\|_{[-\tau, 0]} \\
\geq & \sigma\left\{\int_{\alpha}^{\beta} G\left(\frac{1}{2}, s\right) \bar{M}_{0} d s+\sum_{\alpha<t_{k}<\beta} G\left(\frac{1}{2}, t_{k}\right) \rho\left(t_{k}\right) \bar{M}_{k}\right\}\|u\|_{[-\tau, T]}>b^{*} .
\end{aligned}
$$

Now if we set $\Omega_{b^{*}}=\left\{u \in K:\|u\|_{[-\tau, T]}<b^{*}\right\}$. Then (3.10) shows that $\|S u\|_{[-\tau, T]}>\|u\|_{[-\tau, T]}$ for $u \in \partial \Omega_{b^{*}}$. Thus, an application of Lemma 2.1 again shows that

$$
i\left(S, \Omega_{b^{*}}, K\right)=0
$$

Since $a_{1}<b_{1}<b^{*}$, it follows from (3.5), (3.7), (3.11), and the additivity of the fixed index that

$$
i\left(S, \Omega_{b_{1}} \backslash \bar{\Omega}_{a_{1}}, K\right)=1, \quad i\left(S, \Omega_{b^{*}} \backslash \bar{\Omega}_{b_{1}}, K\right)=-1
$$


Thus, $S$ has a fixed point $u_{*}$ in $\Omega_{b_{1}} \backslash \bar{\Omega}_{a_{1}}$, and a fixed point $u_{* *}$ in $\Omega_{b^{*}} \backslash \bar{\Omega}_{b_{1}}$. They are positive solutions of the PBVP (1.1) and

$$
0<\left\|u_{*}\right\|_{[-\tau, T]}<b_{1}<\left\|u_{* *}\right\|_{[-\tau, T]} .
$$

The proof is complete.

For the second theorem we need the following hypotheses:

(C3) There exists a constant $a_{2}>0$ satisfying

$$
a_{2}>\max \left\{\|\varphi\|_{[-\tau, 0]},\left(1-D^{*}\right)^{-1} A\right\} \quad\left(D^{*}\right. \text { is given in (3.12)), }
$$

such that for $v \in P C^{+}\left(J^{*}\right):\|v\|_{[-\tau, 0]} \leq a_{2}$,

$$
f(t, v) \leq \lambda_{0}^{*}\|v\|_{[-\tau, 0]}, \quad \forall t \in[0, T] \quad \text { and } \quad I_{k}(v) \leq \lambda_{k}^{*}\|v\|_{[-\tau, 0]}, \quad k=1,2, \ldots, m
$$

where $\lambda_{0}^{*}, \lambda_{k}^{*}$ are positive constants satisfying:

$$
D^{*}:=\max _{t \in[0, T]}\left\{\lambda_{0}^{*} \int_{0}^{T} G(t, s) d s+\sum_{k=1}^{m} G\left(t, t_{k}\right) \rho\left(t_{k}\right) \lambda_{k}^{*}\right\}<1 .
$$

(C4) $H_{k}: R^{+} \rightarrow R^{+}(k=1,2, \ldots, m)$ are continuous nonincreasing functions such that $\left|I_{k}(v)\right| \leq H_{k}\left(\|v\|_{[-\tau, 0]}\right)$ for $v \in P C^{+}\left(J^{*}\right)$.

(C5) There exists a constant $b_{2}$ with $b_{2}>a_{2}$ such that for any $v \in P C^{+}\left(J^{*}\right): \sigma b_{2} \leq$ $\|v\|_{[-\tau, 0]} \leq b_{2}$,

$$
f(t, v) \geq \lambda_{0} \max \left\{\|v\|_{[-\tau, 0]},\|\varphi\|_{[-\tau, 0]}\right\}, \quad \forall t \in[0, T]
$$

and

$$
I_{k}(v) \geq \lambda_{k} \max \left\{\|v\|_{[-\tau, 0]},\|\varphi\|_{[-\tau, 0]}\right\}, \quad k=1,2, \ldots, m,
$$

where $\lambda_{0}>0, \lambda_{k}>0$, and

$$
\sigma\left\{\lambda_{0} \int_{\alpha}^{\beta} G\left(\frac{1}{2}, s\right) d s+\sum_{\alpha<t_{k}<\beta} G\left(\frac{1}{2}, t_{k}\right) \rho\left(t_{k}\right) \lambda_{k}\right\} \geq 1 .
$$

Theorem 3.2 Assume that (C3)-(C5), and $f_{\infty}=0$ hold. Then PBVP (1.1) has at least two positive solutions $u_{*}, u_{* *}$ with $0<\left\|u_{*}\right\|_{[-\tau, T]}<b_{2}<\left\|u_{* *}\right\|_{[-\tau, T]}$.

Proof For any $u \in K$ with $\|u\|_{[-\tau, T]}=a_{2}$. According to (2.5) and assumption (C3), we have

$$
\begin{aligned}
|S u(t)| & =\left\{\begin{array}{cc}
\mid \varphi(0)+\frac{(A-\varphi(0))}{\phi(T)} \phi(t)+\int_{0}^{T} G(t, s) f\left(s, u_{s}\right) d s \\
+\sum_{0<t_{k}<T} G\left(t, t_{k}\right) \rho\left(t_{k}\right) I_{k}\left(u_{t_{k}}\right) \mid, & t \in[0, T], \\
|\varphi(t)|, & t \in[-\tau, 0],
\end{array}\right. \\
& \leq\left\{\begin{array}{c}
\max _{t \in[0, T]}\left\{\lambda_{0}^{*} \int_{0}^{T} G(t, s)\left\|u_{s}\right\|_{[-\tau, 0]} d s\right. \\
\left.\quad+\sum_{0<t_{k}<T} G\left(t, t_{k}\right) \rho\left(t_{k}\right) \lambda_{k}^{*}\left\|u_{t_{k}}\right\|_{[-\tau, 0]}\right\}+A, \\
\|\varphi\|_{[-\tau, 0]},
\end{array}\right.
\end{aligned}
$$




$$
\begin{aligned}
& \leq\left\{\begin{array}{l}
D^{*} a_{2}+A, \\
\|\varphi\|_{[-\tau, 0]}
\end{array}\right. \\
& <a_{2} .
\end{aligned}
$$

Set $\Omega_{a_{2}}=\left\{u \in K:\|u\|_{[-\tau, T]}<a_{2}\right\}$. Then (3.13) shows that $\|S u\|_{[-\tau, T]}<\|u\|_{[-\tau, T]}$ for $u \in$ $\partial \Omega_{a_{2}}$. Thus Lemma 2.1 implies

$$
i\left(S, \Omega_{a_{2}}, K\right)=1 .
$$

On the other hand, it follows from (2.5) and assumption (C5) that

$$
\begin{aligned}
(\text { Su })\left(\frac{1}{2}\right)= & \varphi(0)+\frac{(A-\varphi(0))}{\phi(T)} \phi\left(\frac{1}{2}\right)+\int_{0}^{T} G\left(\frac{1}{2}, s\right) f\left(s, u_{s}\right) d s \\
& +\sum_{0<t_{k}<T} G\left(\frac{1}{2}, t_{k}\right) \rho\left(t_{k}\right) I_{k}\left(u_{t_{k}}\right) \\
\geq & \int_{0}^{T} G\left(\frac{1}{2}, s\right) \lambda_{0} \max \left\{\left\|u_{s}\right\|_{[-\tau, 0]},\|\varphi\|_{[-\tau, 0]}\right\} d s \\
& +\sum_{0<t_{k}<T} G\left(\frac{1}{2}, t_{k}\right) \rho\left(t_{k}\right) \lambda_{k} \max \left\{\left\|u_{t_{k}}\right\|_{[-\tau, 0]},\|\varphi\|_{[-\tau, 0]}\right\} \\
\geq & \int_{\alpha}^{\beta} G\left(\frac{1}{2}, s\right) \lambda_{0} \max \left\{\sigma\|u\|_{[0, T]},\|\varphi\|_{[-\tau, 0]}\right\} d s \\
& +\sum_{\alpha<t_{k}<\beta} G\left(\frac{1}{2}, t_{k}\right) \rho\left(t_{k}\right) \lambda_{k} \max \left\{\sigma\|u\|_{[0, T]},\|\varphi\|_{[-\tau, 0]}\right\} \\
\geq & \sigma\left\{\lambda_{0} \int_{\alpha}^{\beta} G\left(\frac{1}{2}, s\right) d s+\sum_{\alpha<t_{k}<\beta} G\left(\frac{1}{2}, t_{k}\right) \rho\left(t_{k}\right) \lambda_{k}\right\}\|u\|_{[-\tau, T]} \\
\geq & \|u\|_{[-\tau, T]}=b_{2} \quad \text { for any } u \in K \text { with }\|u\|_{[-\tau, T]}=b_{2} .
\end{aligned}
$$

Set $\Omega_{b_{2}}=\left\{u \in K:\|u\|_{[-\tau, T]}<b_{2}\right\}$. Then (3.15) implies that $\|S u\|_{[-\tau, T]} \geq\|u\|_{[-\tau, T]}$ for $u \in$ $\partial \Omega_{b_{2}}$. Thus an application of Lemma 2.1 again shows that

$$
i\left(S, \Omega_{b_{2}}, K\right)=0 .
$$

In view of assumption $(\mathrm{C} 4)$ and $f_{\infty}=0$, there are two possibilities:

Case 1 . Suppose that $f$ is unbounded, then there exists a constant $d_{1}$ satisfying:

$$
d_{1}>\max \left\{\|\varphi\|_{[-\tau, 0]}, b_{2}\right\},
$$

such that

$$
f(t, v) \leq \varepsilon_{0}\|v\|_{[-\tau, 0]} \quad \text { for } v \in P C^{+}\left(J^{*}\right):\|v\|_{[-\tau, 0]} \geq d_{1}, \forall t \in[0, T]
$$

and

$$
\left|I_{k}(v)\right| \leq H_{k}\left(\|v\|_{[-\tau, 0]}\right) \leq H_{k}\left(d_{1}\right), \quad k=1,2, \ldots, m,
$$


where $\varepsilon_{0}$ is a positive constant satisfying

$$
\max _{t \in[0, T]}\left\{\varepsilon_{0} d_{1} \int_{0}^{T} G(t, s) d s+\sum_{k=1}^{m} G\left(t, t_{k}\right) \rho\left(t_{k}\right) H_{k}\left(d_{1}\right)\right\}+A \leq d_{1} .
$$

If $u \in K$ with $\|u\|_{[-\tau, T]}=d_{1}$, then it follows from (2.5), (3.17), and (3.18) that

$$
\begin{aligned}
|S u(t)| & \leq\left\{\begin{array}{l}
\max _{t \in[0, T]}\left\{\varepsilon_{0} d_{1} \int_{0}^{T} G(t, s) d s+\sum_{0<t_{k}<T} G\left(t, t_{k}\right) \rho\left(t_{k}\right) H_{k}\left(d_{1}\right)\right\}+A, \\
\|\varphi\|_{[-\tau, 0]}
\end{array}\right. \\
& \leq d_{1} .
\end{aligned}
$$

Case 2. Suppose that $f$ is bounded. Then there exists a constant $N$ such that

$$
|f(t, v)| \leq N, \quad t \in[0, T], \forall v \in P C^{+}\left(J^{*}\right)
$$

Taking

$$
d_{2} \geq \max \left\{\|\varphi\|_{[-\tau, 0]}, \max _{t \in[0, T]}\left\{N \int_{0}^{T} G(t, s) d s+\sum_{0<t_{k}<T} G\left(t, t_{k}\right) \rho\left(t_{k}\right) H_{k}(0)\right\}+A, b_{2}\right\} .
$$

For $u \in K$ and $\|u\|_{[-\tau, T]}=d_{2}$, from (2.5), we have

$$
\begin{aligned}
|S u(t)| & \leq\left\{\begin{array}{l}
\max _{t \in[0, T]}\left\{N \int_{0}^{T} G(t, s) d s+\sum_{0<t_{k}<T} G\left(t, t_{k}\right) \rho\left(t_{k}\right) H_{k}(0)\right\}+A, \\
\|\varphi\|_{[-\tau, 0]}
\end{array}\right. \\
& \leq d_{2} .
\end{aligned}
$$

Choose $d=\max \left\{d_{1}, d_{2}\right\}$. Hence, in either case, we always may set

$$
\Omega_{d}=\left\{u \in K:\|u\|_{[-\tau, T]}<d\right\},
$$

such that $\|S u\|_{[-\tau, T]} \leq\|u\|_{[-\tau, T]}$ for $u \in \partial \Omega_{d}$. Thus, Lemma 2.1 yields

$$
i\left(S, \Omega_{d}, K\right)=1 .
$$

Since $a_{2}<b_{2}<d$, it follows from (3.14), (3.16), (3.20), and the additivity of the fixed point index that

$$
i\left(S, \Omega_{b_{2}} \backslash \bar{\Omega}_{a_{2}}, K\right)=-1, \quad i\left(S, \Omega_{d} \backslash \bar{\Omega}_{b_{2}}, K\right)=1 .
$$

Thus, $S$ has a fixed point $u_{*}$ in $\Omega_{b_{2}} \backslash \bar{\Omega}_{a_{2}}$, and a fixed point $u_{* *}$ in $\Omega_{d} \backslash \bar{\Omega}_{b_{2}}$. They are positive solutions of the PBVP (1.1) and

$$
0<\left\|u_{*}\right\|_{[-\tau, T]}<b_{2}<\left\|u_{* *}\right\|_{[-\tau, T]} .
$$

The proof is complete. 
Example 3.3 Consider the following PBVP:

$$
\left\{\begin{array}{l}
\left(e^{t} u^{\prime}(t)\right)^{\prime}=\left(1+t^{2}\right) F\left(\sup _{\theta \in[-1,0]}\left|u_{t}(\theta)\right|\right) \\
-\Delta u^{\prime}\left(\frac{1}{2}\right)=I\left(\sup _{\theta \in[-1,0]}\left|u\left(\frac{1}{2}+\theta\right)\right|\right), \\
u(t)=\frac{1}{20}(1+\sin t), \quad t \in[-1,0], \quad u(1)=2,
\end{array}\right.
$$

where

$$
F(x)=\left\{\begin{array}{ll}
1-\sqrt{x}, & x \in[0,0.25), \\
2 x, & x \in[0.25,20), \\
\frac{1}{10} x^{2}, & x \in[20,+\infty),
\end{array} \quad I(x)= \begin{cases}x+0.8, & x \in[0,0.6), \\
\frac{7}{3} x, & x \in[0.6,21), \\
\frac{1}{147} x^{3}-14, & x \in[21,+\infty) .\end{cases}\right.
$$

Then PBVP (3.21) has at least two positive solutions $u_{*}, u_{* *}$ with $0<\left\|u_{*}\right\|_{[-1,1]}<10<$ $\left\|u_{* *}\right\|_{[-1,1]}$.

Proof PBVP (3.21) can be regarded as a PBVP of the form (1.1), where

$$
f(t, x)=\left(1+t^{2}\right) F(\|x\|), \quad I_{1}(x)=I(\|x\|), \quad \varphi(t)=\frac{1}{20}(1+\sin t),
$$

and $\rho(t)=e^{t}, A=2, \tau=-1, T=1$.

First we have $1-\int_{0}^{1} G(s, s) d s \approx 0.8980$. By choosing $\alpha=0.25, \beta=0.75$, we get $\sigma=$ $0.2543<1$. On the other hand, it follows from (3.21) and (3.22) that $f_{\infty}=\infty$ and $I_{1}^{\infty}=\infty$ are satisfied. Finally, we show that (C1) and (C2) hold. Choose $M_{0}=10, M_{1}=16, a_{1}=\frac{1}{25}$, $b_{1}=10, M_{0}^{*}=2, M_{1}^{*}=\frac{7}{3}$. By calculation, we get

$$
\sigma\left\{M_{0} \int_{0.25}^{0.75} G\left(\frac{1}{2}, s\right) d s+G\left(\frac{1}{2}, \frac{1}{2}\right) \rho\left(\frac{1}{2}\right) M_{1}\right\} \approx 1.0868>1, \quad D \approx 0.7754
$$

and

$$
\max \left\{\|\varphi\|_{[-\tau, 0]}, a_{1},(1-D)^{-1} A\right\} \approx 8.9048<b_{1}=10 .
$$

Then it is not difficult to see that the conditions (C1) and (C2) hold.

By Theorem 3.1, PBVP (3.21) has at least two positive solutions $u_{*}, u_{* *}$ with $0<$ $\left\|u_{*}\right\|_{[-1,1]}<10<\left\|u_{* *}\right\|_{[-1,1]}$.

\section{Competing interests}

The authors declare that they have no competing interests.

\section{Authors' contributions}

The authors declare that the study was realized in collaboration with the same responsibility. All authors read and approved the final manuscript.

\section{Author details}

'School of Science, Hunan University of Technology, Zhuzhou, Hunan 412007, P.R. China. ${ }^{2}$ Department of Mathematics, Central South University, Changsha, Hunan 410075, P.R. China. ${ }^{3}$ School of Electrical and Information Engineering, Hunan University of Technology, Zhuzhou, Hunan 412007, P.R. China.

\section{Acknowledgements}

The authors are highly grateful for the referees' careful reading and comments on this paper. The research is supported by Hunan Provincial Natural Science Foundation of China (Nos. 13JJ3106 and 12JJ2004); it is also supported by the National Natural Science Foundation of China (Nos. 61074067 and 11271372). 


\section{References}

1. Bainov, DD, Simeonov, PS: Systems with Impulse Effect. Ellis Horwood, Chichester (1989)

2. Lakshmikantham, V, Bainov, DD, Simeonov, PS: Theory of Impulsive Differential Equations. World Scientific, Singapore (1989)

3. Guo, D: Multiple positive solutions for $n$ th-order impulsive integro-differential equations in Banach spaces. Nonlinear Anal. 60, 955-976 (2005)

4. Dong, Y: Periodic boundary value problems for functional differential equations with impulses. J. Math. Anal. Appl. 210, 170-182 (1997)

5. Ma, R: Positive solutions for boundary value problems of functional differential equations. Appl. Math. Comput. 193, 66-72 (2007)

6. He, Z, Yu, J: Periodic boundary value problem for first-order impulsive ordinary differential equations. J. Math. Anal. Appl. 272, 67-78 (2002)

7. Zhao, Y, Chen, H: Multiplicity of solutions to two-point boundary value problems for second-order impulsive differential equation. Appl. Math. Comput. 206, 925-931 (2008)

8. Huseynov, A: Positive solutions of a nonlinear impulsive equation with periodic boundary conditions. Appl. Math Comput. 217, 247-259 (2010)

9. Mohamed, M, Ahmad, HS, Noorani, MSM: Periodic boundary value problems for systems of first-order differential equations with impulses. Differential and Difference Equations with Applications. Springer Proceedings in Mathematics and Statistics, vol. 47, pp. 525-534 (2013)

10. Jankowski, T: Positive solutions for second order impulsive differential equations involving Stieltjes integral conditions. Nonlinear Anal. 74, 3775-3785 (2011)

11. Tian, Y, Jiang, D, Ge, W: Multiple positive solutions of periodic boundary value problems for second order impulsive differential equations. Appl. Math. Comput. 200, 123-132 (2008)

12. Zhang, D, Dai, B: Infinitely many solutions for a class of nonlinear impulsive differential equations with periodic boundary conditions. Comput. Math. Appl. 61, 3153-3160 (2011)

13. Ding, W, Han, M, Mi, J: Periodic boundary value problem for the second-order impulsive functional differential equations. Comput. Math. Appl. 50, 491-507 (2005)

14. Li, J, Nieto, JJ, Shen, J: Impulsive periodic boundary value problems of first-order differential equations. J. Math. Anal. Appl. 325, 226-236 (2007)

15. Liang, R, Shen, J: Periodic boundary value problem for the first-order impulsive functional differential equations. J. Comput. Appl. Math. 202, 498-510 (2007)

16. Liu, Y: Further results on periodic boundary value problems for nonlinear first-order impulsive functional differential equations. J. Math. Anal. Appl. 327, 435-452 (2007)

17. Nieto, JJ: Basic theory for nonresonance impulsive periodic problems of first order. J. Math. Anal. Appl. 205, 423-433 (1997)

18. Chen, L, Sun, J: Nonlinear boundary value problem of first-order impulsive integro-differential equations. J. Comput. Appl. Math. 202, 392-401 (2007)

19. Liu, Y: Periodic boundary value problems for first order functional differential equations with impulse. J. Comput. Appl. Math. 223, 27-39 (2009)

20. Jiang, D, Nieto, JJ, Zuo, W: On monotone method for first and second-order periodic boundary value problems and periodic solutions of functional differential equations. J. Math. Anal. Appl. 289, 691-699 (2004)

21. Yang, $X$, Shen, J: Nonlinear boundary value problems for first-order impulsive functional differential equations. Appl. Math. Comput. 189, 1943-1952 (2007)

22. Thaiprayoon, C, Samana, D, Tariboon, J: Periodic boundary value problems for second-order impulsive integro-differential equations with integral jump conditions. Bound. Value Probl. 2012, 122 (2012)

23. Wang, G, Zhang, L, Song, G: New existence results and comparison principles for impulsive integral boundary value problem with lower and upper solutions in reversed order. Adv. Differ. Equ. 2011, Article ID 783726 (2011)

24. Zhao, Y, Chen, $\mathrm{H}$ : Existence of multiple positive solutions for singular functional differential equation with sign-changing nonlinearity. J. Comput. Appl. Math. 234, 1543-1550 (2010)

25. Guo, D, Lakshmikantham, V: Nonlinear Problems in Abstract Cone. Academic Press, Orlando (1988)

10.1186/1687-1847-2014-134

Cite this article as: Zhao et al.: Periodic boundary value problems for second-order functional differential equations with impulse. Advances in Difference Equations 2014, 2014:134

\section{Submit your manuscript to a SpringerOpen ${ }^{\ominus}$ journal and benefit from:}

- Convenient online submission

- Rigorous peer review

- Immediate publication on acceptance

- Open access: articles freely available online

- High visibility within the field

- Retaining the copyright to your article 